\title{
Editorial
}

\section{John Bynner}

Executive Editor

\section{Open Access for All (AFA)}

These are turbulent times for journal publishing. Under the economic restraints of university budget cuts, the costs to university libraries of purchasing downloading rights to papers published in commercially-produced journals is becoming more than many can bear. Over one million dollars per annum is not uncommon, leading Harvard's Chief Librarian to announce that 'enough is enough'. The 3.5 million dollars Harvard currently spends on academic journals is 'unsustainable".

The alternative approach is to bypass commerce by publishing research in open access on-line journals of which LLCS is a typical example. Our contribution to the debate is to argue for some diversion of library funds to support such journalsii.

Despite the huge help of the Creative Commons license for free access to Open Journal System (OJS) software, article processing costs (APCs) - ranging from managing peer review, to layout and proof reading - still have to be met. The funding model advocated for Open Access journals typically relies on the principle of 'payment to publish', i.e. meeting APCs through payment: first, to submit a paper and second, if the paper is accepted, payment to publish it in the journal. Such fees can range from a few hundred to a few thousand dollars per article and may be waived in special cases but only at the publisher's discretion.

Many Research Councils and major Foundations such as the Wellcome Trust are already including in their research grants, a funding component to meet the APC. But this approach still risks excluding those without access to similar funding, especially researchers in developing countries. It also hands over an element of control of what's published to the research funder, at the expense of the research community in partnership with the journals that serve it.

LLCS was fortunate in benefiting from a three year development grant from the Nuffield Foundation to help the journal get established. But now in the third year of publication, and on the ninth issue, we have had to seek alternative sources of support. The new Society for Longitudinal and Life Course Studies iii, now publisher of the journal, is one such source that will, over time, build membership to a point where fee income meets costs. In the interim we are most grateful for the support coming through three year co-sponsorship agreements with the VU (Free University) of Amsterdam Medical Center (Department of Psychiatry) and the Institute of Social and Economic Research, University of Essex - and we hope, more to come. As one other safeguard, it has been decided that, beginning with the next issue in October 2012, a small annual reader registration fee of $£ 20$ (or Euro and Dollar equivalents) will be introduced from which Society members will be exempt.

The more general point is that new on-line journals need to be supported to meet the communication needs of an ever-broadening spectrum of research interests. To achieve the highest academic and publishing standards, such journals need much nurturing in their early years, to establish reputation and build the readership and authorship base on which the journal's long-term viability will depend. Every LLCS reader and writer is urged to join us in the campaign to make the free and universal circulation of research knowledge a reality.

\section{Current Issue}

This Issue exemplifies the wide range of content and modes of communication that the LLCS has to offer. The scene is set with a Special Section, the origins of which were papers from a co-ordinated programme of secondary analysis of longitudinal data presented at the society's first annual conference in Clare College, Cambridge. The theme is 'Transition to adulthood in the UK, US and Finland': the form it takes in the domains of education, employment, partnership and family formation and the changes taking place in it over a twelve year interval. The focus of analysis is on role statuses in the mid-twenties as outcomes of the transition using latent class analysis to identify their main configurations. Multinomial logistic regression is used to model antecedent conditions and wellbeing outcomes later in life. A key contribution of the Section is to signal the value of such 
configurational analysis for comparative life course research within and across countries over comparable timeframes, as part of an ever-widening cross-national research agenda.

The following Individual Paper, focuses on a particular part of this broader landscape using the UK Millennium Cohort Study to investigate the role of fathers in moderating the effects of adverse life events and family economic disadvantage on early behavioural and emotional difficulties in infancy ( 9 months and three years). The findings point to economic disadvantage and emotional difficulty as where the main connections lie.

The next paper under our Study Profiles section heading is devoted to the University of Michiganbased Panel Study of Income Dynamics (PSID). With 44 years of data collection behind it, the PSID is the foundation stone of all household panel studies worldwide and the harmonized 'Cross-National Equivalent File (CNEF) combining eight of them. The rich profile describes both the origins of and future plans for PSID - a benchmarking document for the field. LLCS is looking forward to many more examples of such profiles, so do keep sending them in. Guidance on writing them is available on the Journal's 'ABOUT' page iv $^{\text {iv }}$

Finally, we complete the Issue under another of the journal's section sub-heads - Comment and Debate. An important paper published three issues back challenged the idea of 'income returns' to higher education in favour of 'social class returns' as measured by entry into the salariat. A statistician and two labour market sociologists discuss from their different perspectives, methodological and substantive issues raised by the study to which the authors respond. The product is a fascinating debate raising key social science issues such as establishing causality and the concept of social mobility - not to be missed!

\section{Over to you}

LLCS thrives on the flow of communications between authors, reviewers and editors, where surpluses if not excessive are generally a good thing. We welcome papers across the whole range of the journal's interests especially those that began life in an SLLS conference where member involvement has been part of the process of their production. Peer review is the life blood of the first class academic journal and we need to broaden continually our panel for doing it especially in the field of inter-disciplinary life course science and internationally. If you are interested, write to me or any of the other Section Editors, with details of your reviewing interest and experience - find us at http://www.llcsjournal.org/index.php/llcs/about/ed itorialTeam We look forward to hearing from you.

\footnotetext{
' http://www.guardian.co.uk/science/2012/apr/24/harvard-university-journal-publishers-prices

ii http://www.guardian.co.uk/science/blog/2012/may/09/open-access-publishing-deep-pockets

iii http://www.slls.org.uk

iv http://www.Ilcsjournal.org/index.php/llcs/about/submissions\#authorGuidelines
}

\section{European Child Cohort Network and SLLS International Conference, PARIS, 29-31 October 2012 'Childhood and beyond: tracing cohorts across the lifecourse'}

The third conference of the Society for Longitudinal and Life Course Studies (SLLS) is being held jointly with the final conference of the European Science Foundation-funded European Child Cohort Network (EUCCONET).

\section{Keynote addresses by:}

Dr Marie-Aline Charles, INSERM, Director of the French child cohort ELFE, 'Early origins of obesity'

Professor Jane Waldfogel, Columbia University, 'Socio-economic inequality in childhood and beyond: international evidence from cohort studies'

Professor lan Deary, Centre for Cognitive Ageing and Cognitive Epidemiology University of Edinburgh, 'From 11 to 90: following up the Scottish Mental Surveys of 1932 and 1947'

More information: http://www.longstudies.longviewuk.com/pages/conference.shtml 